\title{
Overlooked Risks of Biochars: Persistent Free Radicals trigger Neurotoxicity in Caenorhabditis elegans
}

Thora Lieke @ https://orcid.org/0000-0002-4345-1712, Xuchao Zhang, Christian E. W. Steinberg,

Bo Pan (1) https://orcid.org/0000-0003-3680-1451

DOI

10.1021/acs.est.8b01338

Original publication date

19 June 2018 (Available online)

\section{Document version}

Accepted manuscript

Published in

Environmental Science and Technology

Citation

Lieke T, Zhang X, Steinberg CEW, Pan B. Overlooked risks of biochars: persistent free radicals trigger neurotoxicity in Caenorhabditis elegans. Environmental Science and Technology. 2018;52(14):7981-7. 


\section{Overlooked Risks of Biochars - Persistent Free Radicals trigger Neurotoxicity in C. elegans}

Thora LIEKE ${ }^{\mathrm{a}, \mathrm{b}, \mathrm{c}^{*}}$, Xuchao ZHANG ${ }^{\mathrm{a}}$, Christian E.W. STEINBERG ${ }^{\mathrm{b}}$, Bo PAN ${ }^{\mathrm{a},{ }^{*}}$

${ }^{a}$ Faculty of Environmental Science and Engineering, Kunming University of Science and Technology, 650500 Kunming, China

${ }^{\mathrm{b}}$ Faculty of Life Sciences, Freshwater and Stress Ecology, Humboldt Universität zu Berlin,

Späthstr. 80/81, 12437 Berlin, Germany

'Leibniz Institute of Freshwater Ecology and Inland Fisheries, Müggelseedamm 310, 12587 Berlin,

Germany

*Corresponding authors (lieke@igb-berlin.de; panbocai@aliyun.com)

Keywords: electron paramagnetic resonance spectroscopy; hormesis; acute environmental toxicology; neurobehavior; $\mathrm{PAH}$; potential toxic elements

\section{Abstract}

In recent years, biochars have gained increasing interest in mitigating climate changes and revitalizing contaminated or drained soil. Studies determining their impact on the ecosystem, especially on soil invertebrates, however, are still scarce and the neurotoxic potential of biochars has never been evaluated before. Using the model organism Caenorhabditis elegans we determined the neurotoxic effect of biochar produced from rice straw by pyrolysis at $500^{\circ} \mathrm{C}$ at concentrations ranging from 0 to $2000 \mathrm{mg} \mathrm{C} \cdot \mathrm{L}^{-1}$. Biochar had a hormetic effect on locomotion behavior. Furthermore, high concentrations impaired defecation as well as the recognition and response to a chemical attractant. None of the potential toxic chemicals in the biochar had sufficient high concentrations to explain the detected neurotoxic effect. 
Using electron paramagnetic resonance (EPR) spectroscopy, we detected free radicals in the biochar.

Detrimental reaction of free radicals with biotic macromolecules can induce oxidative stress responses and are a potential reason for the evaluated neurotoxic effect of biochar. Overall, we were able to prove that biochars have the potential to act as weak neurotoxins to soil organisms and effects of persistent free radicals should be investigated further.

\section{Introduction}

Biochar is obtained from thermochemical conversion (carbonization) of organic material under oxygen-limited conditions at temperatures between $275^{\circ} \mathrm{C}$ and $700^{\circ} \mathrm{C}$. In contrast to fossil fuels, which are 'carbon positive' and therefore add more carbon dioxide to the atmosphere than fixing from it, biochars can be 'carbon negative' by transforming the carbon of the biomass into stable carbon structures and thereby reducing the emission by otherwise naturally degraded biomass ${ }^{1,2}$. Therefore, biochars have recently gained special interest in mitigating climate change. According to Woolf et al. ${ }^{3}$ sustainable implementation of biochar is estimated to have the potential to reduce the annual anthropogenic net emission of greenhouse-gases (carbon dioxide, methane, and nitrous oxide) by a maximum of $1.8 \mathrm{Gt} \mathrm{CO}_{2}-\mathrm{C}$ equivalents (about $12 \%$ of current annual emission). In addition to long-term sequestering of atmospheric carbon dioxide, biochars can remediate and restore contaminated soil by adsorbing contaminants to their large surface area and thus reducing their bioavailability ${ }^{4,5}$. Depending on production conditions and feedstock, composition and chemical structure of the resulting biochar can vary considerably. Increasing carbonization temperature gradually from $150^{\circ} \mathrm{C}$ to $550^{\circ} \mathrm{C}$ resulted in decreasing amounts of hydroxy (-OH) and alkyl groups $\left(-\mathrm{CH}_{3}\right)$ and increasing amounts of double bonds $(-\mathrm{C}=\mathrm{C}-)$, suggesting a change from aliphatic to aromatic carbon structures ${ }^{6,7}$.

While biochars have a great potential in reducing atmospheric carbon dioxide content and revitalizing contaminated soil, their ecological effects must be determined carefully prior to largescale applications. In a meta-analysis, Biederman and Harpole ${ }^{8}$ provided a quantitative review of the 
effects of biochar on multiple ecosystem functions and believed that biochar application is a 'winwin-win solution' to energy, carbon storage, and ecosystem function. This statement is heavily debated by Jeffrey et al. ${ }^{9}$, who provided an earlier meta-analysis with mixed results ${ }^{10}$. In more details, studies, comparing microbial community compositions of a carbon rich anthrosol (Amazonian dark earth, Terra preta de Indio) and adjacent soils, found higher total numbers of bacteria as well as a higher diversity of bacteria families inside the anthrosol ${ }^{11,12}$. The underlying mechanism for this phenomenon is likely the porous nature of biochars, providing habitats, nutrients and protection from grazers for the microbiota. Furthermore, enhancement of plant germination, growth and yield has been reported repeatedly, especially in combination with additional fertilization ${ }^{13-15}$. These benefits, however, often lack when biochar is applied alone ${ }^{16,17}$. Apart from seeds and roots of plants, soil fauna, especially invertebrates, is particularly exposed to biochar supplemented into soil. Nevertheless, studies on the effect of biochar to these organisms are scarce and contradictory. Recently, Malev et al. ${ }^{18}$ reported an increased uptake of polycyclic aromatic hydrocarbons (PAHs) by the earthworm Eisenia fetida due to the presence of biochars. On the other hand, Gomez-Eyles et al. ${ }^{19}$ found that the addition of biochar reduced the total as well as the bioavailable concentration of PAHs, but at the same time impaired the growth of the generally pollution tolerant Eisenia spp.. Comparing the effect of biochars from different raw materials, Liesch et al. ${ }^{20}$ determined that pine chip biochar had no effect on growth and survival, while biochar from poultry litter caused $100 \%$ mortality to E. fetida, if applied at high concentrations. In contrast to this, Van Zwieten et al. ${ }^{21}$ found that earthworms prefer biochar-amended soil over control soil. Data on the response of nematodes to direct biochar exposure is even more seldom. Liang et al. ${ }^{22}$ and Zhang et al. ${ }^{23}$ found that addition of biochar to the soil had no effect on the total nematode abundance. The abundance of fungivorous nematodes, however, was significantly increased, probably due to increased growth of edible fungi ${ }^{24}$. Adverse effects using an extract of biochar have also been detected using the model nematode Caenorhabditis elegans ${ }^{25}$ were a gene homolog to the human key anticancer gene $p 53$ was repressed. The P53 protein has been described as "the guardian of the genome" referring to its 
role in conserving stability by preventing genome ${ }^{26}$ and thus tumor formation. Consequently, the down-regulation of this gene bears the risk of an adverse impact on life history traits.

As the soil biota is important to the function of soils and provides many essential ecosystem services, a deeper understanding of interactions between biochar and soil biota is essential. In the present study, we therefore chose used the recently developed neurotoxicity assays with C. elegans ${ }^{27,28}$ to evaluate the impact of biochar on neurophysiological traits in order to assess the risk of wide-broad application of biochar and to determine the underlying mechanisms. Neurotoxicity variables respond to exposure much more sensitive and earlier than other traits, such as health or longevity. Because $C$. elegans belongs to the feeding type of bacterivorous nematodes, and bacterivory by nematodes, in turn, plays a crucial role in the nutrient recycling in and productivity of soils ${ }^{29,30}$, any impairment of the bacterivory by nematodes risks this ecosystem service.

\section{Material and Methods}

\section{Strains}

All experiments were performed using the wild-type C. elegans strain N2 (var. Bristol). Nematodes were maintained on $96 \mathrm{~mm}$ nematode growth medium (NGM) plates at $20^{\circ} \mathrm{C}$ seeded with $1 \mathrm{~mL}$ Escherichia coli strain OP50 ${ }^{31,32}$. Both, N2 and OP50 were obtained from the Caenorhabditis Genetics Center (CGC) (University of Minnesota, USA).

\section{Elemental Analysis}

Content of carbon, nitrogen, hydrogen, sulphur and oxygen was determined after high temperature combustion using a vario MICRO cube (Elementar Analysensystem, Langenselbold, Germany).

\section{Biochar and Exposure Conditions}

Biochar was produced from washed and dried rice straw which was collected in Wujiaying Residential District, Chenggong, Kunming City, Yunnan Province, China $\left(24.8^{\circ} \mathrm{N} ; 102.8^{\circ} \mathrm{E}\right)$. The feedstock was 
dried, chopped and milled to pass a 100 mesh sieve. Material was pyrolyzed for $2 \mathrm{~h}$ under oxygenlimited conditions in a muffle furnace (Box Type Resistance Furnace SX-4-10, Beijing Ever Bright Medical Treatment Instrument, China) at $500^{\circ} \mathrm{C}$ (temperature increase rate $15^{\circ} \mathrm{C} \cdot \mathrm{min}^{-1} ; \mathrm{N}_{2}$ flow $\left.1.5 \mathrm{~L} \cdot \mathrm{min}^{-1}\right)$. Biochar was grinded and sifted using a 300 mesh sieve. Exposure concentrations were $250,500,1000$, and $2000 \mathrm{mg} \mathrm{C} \cdot \mathrm{L}^{-1}$. With a carbon content of $55.5 \%$ (Table S 1 ) this represents amounts of approximately $0.5 \mathrm{mg}, 1 \mathrm{mg}, 2 \mathrm{mg}$, and $4 \mathrm{mg}$ per plate. Biochar was added only to the $1 \mathrm{~mL}$ feeding bacteria, as uniform distribution inside the NGM agar was not possible.

\section{Electron Paramagnetic Resonance (EPR)-Spectroscopy}

About $1.5 \mathrm{mg}$ of samples were loaded into micropipettes (1.0 mm internal diameter, $125 \mathrm{~mm}$ length) and signal was recorded at room temperature using a Bruker X-band A300-6/1 EPR (Bruker, Billerica, Massachusetts, USA). Modulation frequency was $100 \mathrm{kHz}$ and microwave frequency $9.2-9.9 \mathrm{GHz}$. Sweep width was $100 \mathrm{G}$, modulation amplitude $1.00 \mathrm{G}$, and the resolution in the $\mathrm{X}$ axes was 1024 points. Microwave power was $31 \mathrm{~dB}$ (or $0.131 \mathrm{~mW}$ ). The g-factor was estimated using the Bruker WinEPR Acquisition and Microsoft Office Excel ${ }^{33-35}$.

\section{Neurophysiologic experiments}

Prior to all experiments nematodes were synchronized according to Brenner ${ }^{36}$ and Lewis and Fleming ${ }^{37}$. Synchronized L4 larvae were exposed to different biochar concentrations for $24 \mathrm{~h}$ at $20^{\circ} \mathrm{C}$. Methods used in this study followed the previously developed adaption of vertebrate neurotoxic evaluation to C. elegans ${ }^{27,28}$ and are briefly described below. All assays were repeated at least three times. Measurements were performed using a stereo microscope (Nikon SMZ 1500, Tokyo, Japan) or a microscope (Nikon Eclipse E100, Tokyo, Japan).

\section{Autonomic behavior}

Locomotive behavior was monitored by determining body bends and relative movement speed ${ }^{38}$ under a stereo microscope. A body bend was defined as two complete changes of direction of the anterior part of the nematode during sinusoidal movement. For movement speed, worms were 
transferred to a fresh NGM plate with feeding bacteria and allowed to crawl freely for $20 \mathrm{~s}$. Move length was ascertained by measuring the crawler lanes and corresponding nematode length. Mean body size for each group was used for normalization. Pharyngeal pumping was quantified by counting up and down movement of the grinder over a period of $60 \mathrm{~s}$ using a microscope. Locomotion and pumping was monitored using a Nikon DS-FI2 microscope camera, the Nikon DS-U2 controller and evaluated with NIS-Elements D software (Nikon, Tokyo, Japan). Defecation was evaluated following the protocol from Hart ${ }^{38}$. In short, interval between two posterior body-wall contractions was measured using a stereo microscope.

\section{Mechanical sensory stimulus}

Mechanical sensory perception was conducted as described by Kaplan and Horvitz ${ }^{39}$. In short, the anterior part ('nose') of a single forward moving nematode was touched with a fine hair and reversal movement was scored as response. With short periods of resting, each worm was tested 10 times. In total, 15 nematodes per repeat and treatment were tested. The percentage of positive responses was calculated.

\section{Chemical sensory}

Recognition and response to chemical sensory was conducted following the protocol described by Ward ${ }^{40}$ and Saeki et al. ${ }^{41}$. It is based on the learned attraction of $C$. elegans towards $\mathrm{NaCl}$ during rearing. Assay plates were prepared as following: $5 \mathrm{mM}$ potassium phosphate, $\mathrm{pH} 6.0,1 \mathrm{mM} \mathrm{CaCl}$, $1 \mathrm{mM} \mathrm{MgSO}_{4}, 20 \mathrm{~g}^{*} \mathrm{~L}^{-1}$ agar. Equidistant $(3 \mathrm{~cm})$ away from a starting point a $\mathrm{NaCl}$-spot and a controlspot (distance $4 \mathrm{~cm}$ ) were marked. A sodium chloride gradient was established for $24 \mathrm{~h}$ at the $\mathrm{NaCl}$ spot using an agar plug excised from a $\mathrm{NaCl}$ plate (prepared as above but with the addition of $100 \mathrm{mM} \mathrm{NaCl}$ ). Immediately prior to the assay the agar plug was removed and $1 \mu \mathrm{L} 0.5 \mu \mathrm{M}$ sodium azide was applied to both spots. Per plate 30 previously exposed worms were transferred to startingpoint and incubated for $1 \mathrm{~h}$ at $20^{\circ} \mathrm{C}$. The number of animals around $\mathrm{NaCl}$ - and control-spot was determined using a stereo microscope. The chemical index (Ci) was calculated using equation (1) with $\mathrm{n}_{\mathrm{N}}$ as number of animals within an area of $1.5 \mathrm{~cm}$ from the center of $\mathrm{NaCl}$-spot and $\mathrm{n}_{\mathrm{C}}$ number of 
150

151

\section{Statistical Analysis}

The statistical significance of alterations was calculated using SigmaStat 3.5 software (Systat Software Inc., Erkrath, Germany) and One Way ANOVA test (Holm-Sidak-method). All data is displayed as mean \pm SEM (standard error of the mean). Changes are considered statistically significant if their $p$ value is less than $0.05\left(^{*}\right)$ and less than $0.001\left(^{* *}\right)$.

\section{Results and Discussion}

\section{High concentrated biochar affects neurophysiological behavior}

Locomotion behavior, both relative movement speed and number of body bends, was influenced in the same way by exposure to biochar, namely in a hormetic manner. A concentration of $250 \mathrm{mg} \mathrm{C} \cdot \mathrm{L}^{-1}$ biochar significantly increased the number of body bends per minute from 47 to $51(p=0.007)$ and relative movement speed in $20 \mathrm{~s}$ from 4.5 to $4.9(p=0.02)$ (Figure 1A, 2B; Table S 2). Both, $1000 \mathrm{mg}$ $C \cdot L^{-1}$ and $2000 \mathrm{mg} \mathrm{C} \cdot \mathrm{L}^{-1}$, however, significantly decreased the number of body bends as well as the relative movement. On the contrary, both high concentrations significantly increased the time interval between two defecations from $60 \mathrm{~s}$ to over $65 \mathrm{~s}(\mathrm{p}=0.001$ and $p<0.001$, respectively) (Figure 1C, Table S 3). Exposure to concentrations of biochar below $500 \mathrm{mg} \mathrm{C} \cdot \mathrm{L}^{-1}$ had no impact on defecation. None of the concentrations had any impact on the pumping velocity (Figure 1D; Table S 4Error! Reference source not found.). Affirmative response to mechanical stimulation without any exposure was about $94 \%$ and was not impaired by any of the biochar concentrations (Figure 1E; Table S 5). After exposure to $2000 \mathrm{mg} \mathrm{C} \cdot \mathrm{L}^{-1}$, the chemical sensory had a trend towards impairment (Figure 1F; Table $\mathrm{S} 6$ ), however, due to high deviations, there was no statistically significant difference to the control. 

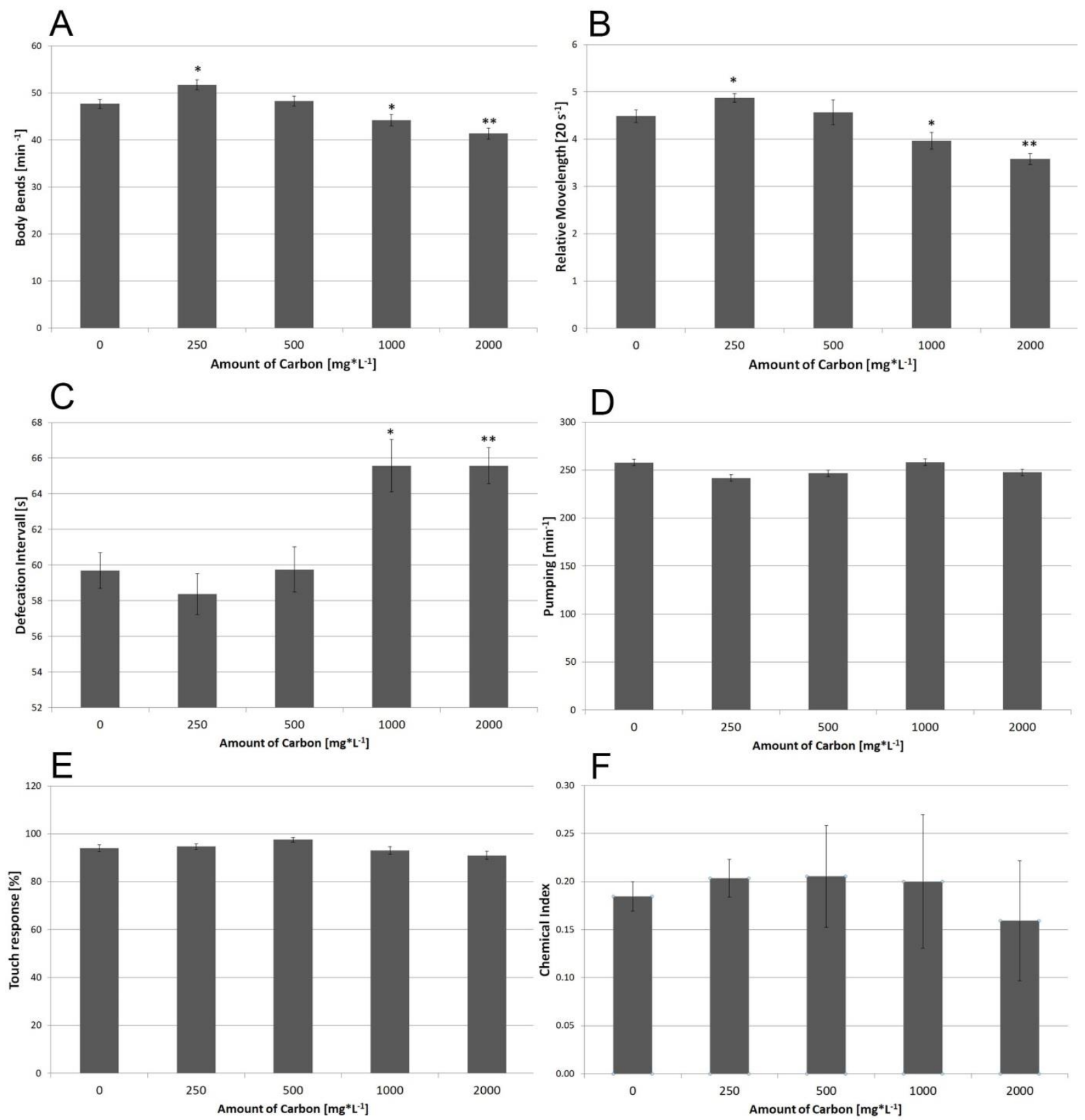

Figure 1: Neurophysiological behavior. Locomotive behavior ((A) body bends and (B) relative move length); (C) Defecation interval; (D) pumping frequency; (E) mechanical sensory and (F) chemical sensory. Significant changes to the control are given by $*(p<0.05)$ and $* *(p>0.001)$. Bars represent mean values \pm SEM (One Way ANOVA (Holm-Sidak-Method)).

Decreased speed of movement impairs not only the ability to reach food, but also to avoid predators and unfavorable conditions. Furthermore with decelerated defecation, the ability to eliminate harmful substances is impaired. In nature, both impaired movement and defecation, can affect survival and fitness of nematodes. Together with the trend to affect chemical sensory, our results demonstrate a neurotoxic effect of high concentrated biochar, which certainly will also occur in field plots treated with biochars, because of mixture of soil and char materials under field conditions. 

on other behavioral traits. This effect, where a compound exerts a stimulatory effect at low concentrations, but is detrimental at high concentrations, is called hormesis ${ }^{42,43}$ and has been reported numerous of times for a large variety of compounds and environmental triggers. The doseresponse of hormesis has been considered an adaptive response. The term 'adaptive response' implies that low- and high-dose exposures should activate analogous response or defense pathways and in consequence the low-dose exposure trains the defense systems to cope with future potentially adverse exposures. Hormesis has been observed in a diverse range of biological systems and, hence, it is unlikely that one single hypothesis is universally applicable ${ }^{44}$. By exploring three natural xenobiotics within the model organism C. elegans, Steinberg et al. ${ }^{45}$ demonstrated that

191 hormesis emerges as one of two types of distinct and specific transcriptional responses to 192 chemically-mediated stress. The occurrence of an adaptive response is seemingly dependent on the 193 molecular characteristics of the chemical. Simple molecules, such as quercetin are more likely to 194 induce an adaptive response than more complex molecules, such as tannic acid or humic substances.

\section{Possible Toxic Elements are unlikely to cause neurotoxic effect}

As a result of production and feedstock, biochar may contain residues of potential toxic elements such as metalloid elements, heavy metals, PAHs, furans, and dioxins. Heavy metals and metalloids are of particular concern on having a negative impact on the environment ${ }^{46}$, including decreasing the 199 diversity and activity of soil invertebrates ${ }^{47}$. Biochar produced from the same batch of raw material as in this study, however, contained only low concentrations of heavy metals and no metalloids ${ }^{35}$.

Concentrations found in this biochar were magnitudes below the evaluated $\mathrm{LC}_{50}{ }^{48}$. Copper, for example, had a concentration of $10.32 \mu \mathrm{g} \cdot \mathrm{L}^{-1}$, while Barsyte et al. ${ }^{49}$ determined the $\mathrm{LC}_{50}$ for copper with $197 \mathrm{mg} \cdot \mathrm{L}^{-1}$. Moyson et al. ${ }^{50}$ determined, that survival rate of $C$. elegans decreased after long 204 term exposure to copper at concentrations of $0.05 \mathrm{mg} \cdot \mathrm{L}^{-1}$. This is, however, still 5 -fold higher than the 205 concentration found in our biochar. Highest concentration of heavy metals in the rice biochar had 206 iron with $226 \mu \mathrm{g} \cdot \mathrm{L}^{-1}$. This is still below any toxic concentration range. One of the very few 
corresponding studies, Wu et al. ${ }^{51}$ evaluated the effect of iron-nano particles on different life traits (locomotion, number of offspring, pumping, defecation, and intestinal autofluorescence) of $C$. elegans and determined acute toxicity only for concentrations above $50 \mathrm{mg} \cdot \mathrm{L}^{-1}$. Furthermore, iron compounds are one major compartment of most soils and as part of the respiratory chain, crucial for life. It is therefore very unlikely that direct toxic effects of metals are the reason for the observed neurotoxic effect of the applied biochar. In addition, total amount measured in the biochar does not necessarily reflect the biological available concentration, since most of the metals are not freely dissolved and, therefore, not bioavailable ${ }^{52}$.

PAHs are formed during combustion and pyrolysis ${ }^{53}$ and the higher condensed ones have been classified as carcinogenic, mutagenic, and teratogenic by the US EPA and the EU, whereby mostly the products, rather than the educts, display the mentioned toxicity ${ }^{54-56}$. Hale et al. ${ }^{57}$ analyzed over 50 biochars of different feedstock and production conditions. Total amount of PAHs ranged from 0.07 $\mu \mathrm{g} \cdot \mathrm{g}^{-1}$ to $3.27 \mu \mathrm{g} \cdot \mathrm{g}^{-1}$, which is below existing environmental quality standards for this type of contamination. Furthermore, concentration of bioavailable PAHs was lower than $10 \mathrm{ng} \cdot \mathrm{g}^{-1}$ in these biochars. Overall concentration of EPA PAHs in the biochar produced from the same raw material as the one used in this study was approximately $100 \mu \mathrm{g} \cdot \mathrm{L}^{-1}$ with $44 \mu \mathrm{g} \cdot \mathrm{L}^{-1}$ benzo[a]pyrene and $30 \mu \mathrm{g} \cdot \mathrm{L}^{-1}$ chrysene ${ }^{35}$. Bioavailable PAHs have been shown to strongly induce cyp35 genes, coding for NADPHdependent monooxygenases involved in bioactivation and detoxification of hydrophobic xenobiotics 58,59 . Toxic concentration, however, was generally above $0.25 \mathrm{mg} \cdot \mathrm{L}^{-1}$ and thereby more than two orders of magnitude higher than PAH concentration measured in a comparable biochar. Therefore, it is unlikely that direct toxicity of PAHs are the reason for the observed effects on neurobehavior of $C$. elegans; this argument gets supported by the fact, that the bioavailable share of the PAHs is usually much lower than the total concentration. Therefore, other potential adverse compounds or structures have to be discussed. We put forward the hypothesis that the trigger for neurotoxic effects in C. elegans are persistent free radicals, since recently, these structures, relatively abundant in biochars as well as humic substances, have been proven toxic ${ }^{60}$. 


\section{Persistent free radicals}

234 Free radicals are molecules with at least one unpaired valence electron in their molecular orbit. They 235 are generated during the thermal degradation into biochar and Liao et al. ${ }^{35}$ showed that type and 236 intensity of these free radicals vary with production conditions and raw material. Time of pyrolysis 237 has a great impact on the intensity of the radical; in situ observation during production of biochar 238 from rice straw showed an increase of intensity of more than four orders of magnitude ${ }^{35}$. With 239 increasing temperature, the type of radicals shifts from oxygen-centered, such as semiquinones, to 240 carbon-centered radicals, such as aromatic radicals. The intensity of the radicals increased as well.

241 Furthermore, structure of EPR spectra varies with the carbon content of the sample ${ }^{61}$.

242 These radicals were stable and persistent for at least over a month. Comparing intensity of radicals in 243 biochar directly after and 1 year after production, we found no significant decrease. In aqueous 244 phase they trigger production of reactive oxygen species (ROS). With the EPR spectroscopy, the 245 resonant microwave absorption of a sample inside a magnet field is measured, providing information on spin concentrations in the material, which are indicative of stable free radicals. Extreme values of EPR intensity of our biochar were about $6.37 \cdot 10^{5}$ and the g-value was 2.0044 indicating a mixture of carbon- and oxygen-centered radicals (Figure 2).
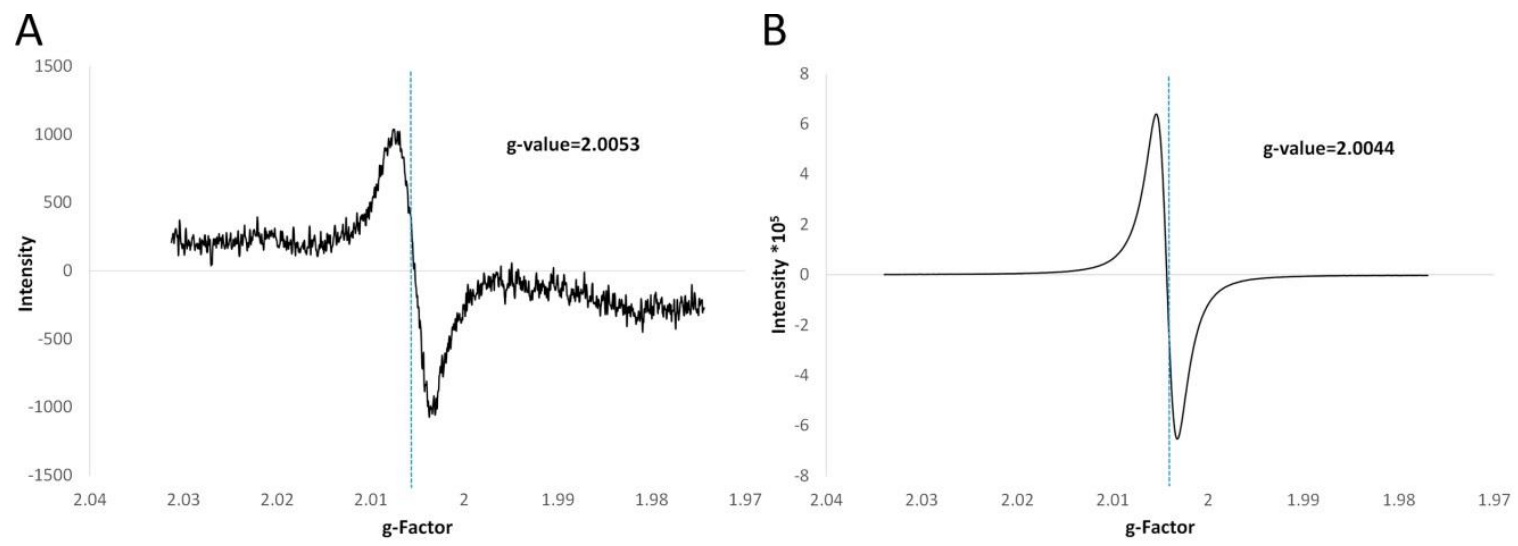

Figure 2: EPR signal detected in (A) feedstock and (B) biochar used.

251 Persistent free radicals or produced ROS can react with many chemical structures including biotic macromolecules, such as glycoproteins leading to destabilization of cellular membranes and cell 
death. In a significant structure-activity-relationship, Steinberg et al. ${ }^{60}$ showed that persistent free radicals reduce the photosynthetic oxygen release of the coon tail (Ceratophyllum demersum). In a recent evaluation of germination, root and shoot length of wheat seedlings, corn seedings, and rice seedlings, biochar displayed a dose-response related inhibition of these traits. Furthermore, plasma membrane of roots exposed to biochar with high EPR intensity was damaged, indicating, that free radicals are reason for the observed inhibitory effects of biochar on seedlings ${ }^{35}$. Disturbance of the homeostatic equilibrium between pro-oxidant and antioxidant by external radicals can lead to oxidative stress and free radical generation. Both have been shown to play a pivotal role in neuronal disorders such as Alzheimer's disease, schizophrenia and Parkinson's disease ${ }^{62,63}$. Furthermore, Ristow ${ }^{64}$ has shown that mild oxidative stress has beneficial effects on locomotion behavior explaining the observed hormetic effect, while application of excesses of dietary antioxidants (vitamins $\mathrm{C}$ and $\mathrm{E}$ ) to invertebrates as well as vertebrates leads to malfunction and dysplasias. This emphasizes our results of biochar, showing a hormetic mode of action. It is therefore very likely that oxidative stress and generation of free radicals are the reasons for the observed neurotoxic effect of biochar. Although the concentrations of PAHs and transient metals were too low to cause any direct toxic effects, both can also be involved in the formation of persistent free radicals in general by interacting with organic radicals through electron transfer. To evaluate if the PFR are caused by PAHs, we extracted $300 \mathrm{mg}$ biochar 5 times with $15 \mathrm{~mL}$ acetonitrile in a in a 40-mL Teflon-lined septum screw cap vial. Each time, the vial was shaken at $25^{\circ} \mathrm{C}$ for 1 hour. Measuring EPR signal before and after extraction (Fig.3) showed no difference in g-value or intensity. Furthermore, Liao et al. showed ${ }^{35}$, that most persistent free radicals in biochar are generated during the cooling process and the associated shrinkage of macromolecules. Thus, PAHs and heavy metals are independent of persistent free radicals in this work. 


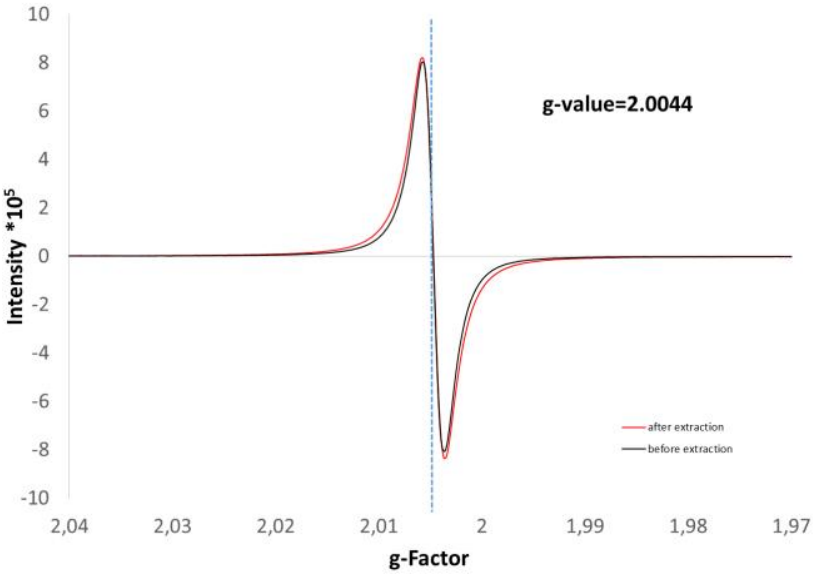

Figure 3: EPR signal of biochar before and after extraction of PAHs using acenitrile.

As mentioned above, Chakrabarti et al. ${ }^{25}$ found the $p 53$ gene down-regulated by Terra preta samples; this finding initiated the search for 'classical' effective chemicals, such as polychlorinated dibenzo-p-dioxins, PAHs, or polychlorinated biphenyls. These chemicals were, however, if at all, found only in traces below any known effective concentration (Dr. J. Kern, Leibniz Institute for Agricultural Engineering Potsdam-Bornim, Germany, pers. communication). Therefore, we assume that persistent free radicals could have been the initiating structure for the gene down-regulation as well, which has generally been neglected.

Our results provide first indications of the neurological risks in a model invertebrate associated with the application of biochar. Furthermore, we were able to point at persistent free radicals as the most likely reason for the observed effects. This assumption, however, needs to be confirmed with further tests; for example, evaluating the internal production of ROS as well as changes of expression of key genes involved in anti-oxidative stress response program and neuronal signal transduction. To confirm our results, further tests, evaluating the effects of soluble and insoluble compartments of the biochar on the neuronal behavior of $C$. elegans might be useful. Notwithstanding that further work is necessary to determine the overall impact of biochar on soil invertebrates and ecosystems, we were able to prove that biochars and other char substrates do not have only beneficial effects, rather they have apparently ambiguous effects on soil organisms. 


\section{Acknowledgements}

This research was supported by National Natural Scientific Foundation of China (41673098 and 41473116), and Yunnan applied basic research project (2016FA040 and 2017IB004).

\section{Conflicts of Interest}

The authors declare that there are no conflicts of interest. The founding sponsors had no role in the design of the study, in the collection, analyses, or interpretation of data or in the writing of the manuscript and the decision to publish the results.

\section{Supporting Information}

Table S1 contains the results of the elemental analysis of the biochar.

Tables S2-S6 contain the data of the neurological behavior tests.

\section{References}

1. Lehmann, J.; Gaunt, J.; Rondon, M., Biochar sequestration in terrestrial ecosystems-a review. Mitigation and Adaptation Strategies for Global Change 2006, 11, (2), 395-419.

2. Laird, D. A., The charcoal vision: a win-win-win scenario for simultaneously producing bioenergy, permanently sequestering carbon, while improving soil and water quality. Agronomy Journal 2008, 100, (1), 178-181.

3. Woolf, D.; Amonette, J. E.; Street-Perrott, F. A.; Lehmann, J.; Joseph, S., Sustainable biochar to mitigate global climate change. Nature Communications 2010, 1, 56.

4. Brändli, R. C.; Hartnik, T.; Henriksen, T.; Cornelissen, G., Sorption of native polyaromatic hydrocarbons (PAH) to black carbon and amended activated carbon in soil. Chemosphere 2008, 73, (11), 1805-1810.

5. Beesley, L.; Marmiroli, M., The immobilisation and retention of soluble arsenic, cadmium and zinc by biochar. Environmental pollution 2011, 159, (2), 474-480.

6. Wu, W.; Yang, M.; Feng, Q.; McGrouther, K.; Wang, H.; Lu, H.; Chen, Y., Chemical characterization of rice straw-derived biochar for soil amendment. Biomass and Bioenergy 2012, 47, 268-276.

7. Brown, R., Biochar Production Technology. In Biochar for Environmental Management: Science and Technology, Lehmann, J.; Joseph, S., Eds. Taylor \& Francis Group: 2009; pp 127-146.

8. Biederman, L. A.; Harpole, W. S., Biochar and its effects on plant productivity and nutrient cycling: a meta - analysis. Global Change Biology Bioenergy 2013, 5, (2), 202-214.

9. Jeffery, S.; Verheijen, F. G. A.; Bastos, A. C.; Velde, M., A comment on 'Biochar and its effects on plant productivity and nutrient cycling: a meta - analysis': on the importance of accurate 
reporting in supporting a fast - moving research field with policy implications. Global Change Biology Bioenergy 2014, 6, (3), 176-179.

10. Jeffery, S.; Verheijen, F. G. A.; van der Velde, M.; Bastos, A. C., A quantitative review of the effects of biochar application to soils on crop productivity using meta-analysis. Agriculture, Ecosystems \& Environment 2011, 144, (1), 175-187.

11. Kim, J.-S.; Sparovek, G.; Longo, R. M.; De Melo, W. J.; Crowley, D., Bacterial diversity of terra preta and pristine forest soil from the Western Amazon. Soil Biology and Biochemistry 2007, 39, (2), 684-690.

12. O’Neill, B.; Grossman, J.; Tsai, M. T.; Gomes, J. E.; Lehmann, J.; Peterson, J.; Neves, E.; Thies, J. E., Bacterial community composition in Brazilian anthrosols and adjacent soils characterized using culturing and molecular identification. Microbial ecology 2009, 58, (1), 23-35.

13. Graber, E. R.; Harel, Y. M.; Kolton, M.; Cytryn, E.; Silber, A.; David, D. R.; Tsechansky, L.; Borenshtein, M.; Elad, Y., Biochar impact on development and productivity of pepper and tomato grown in fertigated soilless media. Plant and Soil 2010, 337, (1-2), 481-496.

14. Asai, H.; Samson, B. K.; Stephan, H. M.; Songyikhangsuthor, K.; Homma, K.; Kiyono, Y.; Inoue, Y.; Shiraiwa, T.; Horie, T., Biochar amendment techniques for upland rice production in Northern Laos: 1. Soil physical properties, leaf SPAD and grain yield. Field Crops Research 2009, 111, (1), 81-84. 15. Blackwell, P.; Riethmuller, G.; Collins, M., Biochar application to soil. In Biochar for Environmental Management: Science and Technology, Lehmann, J.; Joseph, S., Eds. Taylor \& Francis Group: 2009; Vol. 1, pp 207-226.

16. Mikan, C. J.; Abrams, M. D., Altered forest composition and soil properties of historic charcoal hearths in southeastern Pennsylvania. Canadian Journal of Forest Research 1995, 25, (5), 687-696.

17. Chan, K. Y.; Van Zwieten, L.; Meszaros, I.; Downie, A.; Joseph, S., Agronomic values of greenwaste biochar as a soil amendment. Soil Research 2008, 45, (8), 629-634.

18. Malev, O.; Contin, M.; Licen, S.; Barbieri, P.; De Nobili, M., Bioaccumulation of polycyclic aromatic hydrocarbons and survival of earthworms (Eisenia andrei) exposed to biochar amended soils. Environmental Science and Pollution Research 2016, 23, (4), 3491-3502.

19. Gomez-Eyles, J. L.; Sizmur, T.; Collins, C. D.; Hodson, M. E., Effects of biochar and the earthworm Eisenia fetida on the bioavailability of polycyclic aromatic hydrocarbons and potentially toxic elements. Environmental pollution 2011, 159, (2), 616-622.

20. Liesch, A. M.; Weyers, S. L.; Gaskin, J. W.; Das, K. C., Impact of two different biochars on earthworm growth and survival. Annals of Environmental Science 2010, 4, (1), 1-9.

21. Van Zwieten, L.; Kimber, S.; Morris, S.; Chan, K. Y.; Downie, A.; Rust, J.; Joseph, S.; Cowie, A., Effects of biochar from slow pyrolysis of papermill waste on agronomic performance and soil fertility. Plant and Soil 2010, 327, (1-2), 235-246.

22. Liang, W.; Lou, Y.; Li, Q.; Zhong, S.; Zhang, X.; Wang, J., Nematode faunal response to longterm application of nitrogen fertilizer and organic manure in Northeast China. Soil Biology and Biochemistry 2009, 41, (5), 883-890.

23. Zhang, X.-K.; Li, Q.; Liang, W.-J.; Zhang; Bao, X.-L.; Xie, Z.-B., Soil Nematode Response to Biochar Addition in a Chinese Wheat Field. Pedosphere 2013, 23, (1), 98-103.

24. Atkinson, C. J.; Fitzgerald, J. D.; Hipps, N. A., Potential mechanisms for achieving agricultural benefits from biochar application to temperate soils: a review. Plant and Soil 2010, 337, (1-2), 1-18.

25. Chakrabarti, S.; Kern, J.; Menzel, R.; Steinberg, C. E. W., Selected natural humic materials induce and char substrates repress a gene in Caenorhabditis elegans homolog to human anticancer p53. Annals of Environmental Science 2011.

26. Strachan, T.; Read, A. P., Human molecular genetics. Taylor \& Francis Grou: 210.

27. Lieke, T.; Steinberg, C. E. W.; Ju, J.; Saul, N., Natural marine and synthetic xenobiotics get on nematode's nerves: neuro-stimulating and neurotoxic findings in Caenorhabditis elegans. Marine drugs 2015, 13, (5), 2785-2812.

28. Ju, J.; Lieke, T.; Saul, N.; Pu, Y.; Yin, L.; Kochan, C.; Putschew, A.; Baberschke, N.; Steinberg, C. E. W., Neurotoxic evaluation of two organobromine model compounds and natural $\mathrm{AOBr}$-containing 
surface water samples by a Caenorhabditis elegans test. Ecotoxicology and Environmental Safety 2014.

29. Trap, J.; Bonkowski, M.; Plassard, C.; Villenave, C.; Blanchart, E., Ecological importance of soil bacterivores for ecosystem functions. Plant and Soil 2016, 398, (1-2), 1-24.

30. Gebremikael, M. T.; Steel, H.; Buchan, D.; Bert, W.; De Neve, S., Nematodes enhance plant growth and nutrient uptake under $\mathrm{C}$ and $\mathrm{N}$-rich conditions. Scientific reports 2016, 6 .

31. Brenner, S., The genetics of behavior. British medical bulletin 1973, 29, 269-271.

32. Stiernagle, T., Maintenance of $C$. elegans. In WormBook : the online review of $C$. elegans biology, Community, T. C. e. R., Ed. 2006; pp 1-11.

33. Weil, J. A.; Bolton, J. R., Electron Paramagnetic Resonance: Elementary Theory and Practical Applications. John Wiley \& Sons: 2007.

34. Dodd, N. J. F., Magnetic Resonance of Biomolecules: An Introduction to the Theory and Practice of NMR and ESR in Biological Systems. International Journal of Radiation Biology and Related Studies in Physics, Chemistry and Medicin 1977.

35. Liao, S.; Pan, B.; Li, H.; Zhang, D.; Xing, B., Detecting free radicals in biochars and determining their ability to inhibit the germination and growth of corn, wheat and rice seedlings. Environmental science \& technology 2014, 48, (15), 8581-8587.

36. Brenner, S., The genetics of Caenorhabditis elegans. Genetics 1974, 77, (1), 71-94.

37. Lewis, J. A.; Fleming, J. T., Basic culture methods. Methods in cell biology 1995, 48, 3-29.

38. Hart, A. C., Behavior. In WormBook : the online review of C. elegans biology, The C. elegans Research Community: 2006.

39. Kaplan, J. M.; Horvitz, H. R., A dual mechanosensory and chemosensory neuron in Caenorhabditis elegans. Proceedings of the National Academy of Sciences of the United States of America 1993, 90, (6), 2227-31.

40. Ward, S., Chemotaxis by the nematode Caenorhabditis elegans: Identification of attractants and analysis of the response by use of mutants. Proceedings of the National Academy of Sciences of the United States of America 1973, 70, (3), 817-21.

41. Saeki, S.; Yamamoto, M.; lino, Y., Plasticity of chemotaxis revealed by paired presentation of a chemoattractant and starvation in the nematode Caenorhabditis elegans. Journal of Experimental Biology 2001, 204, (Pt 10), 1757-64.

42. Calabrese, E. J., Hormesis: why it is important to toxicology and toxicologists. Environmental Toxicology and Chemistry 2008, 27, (7), 1451-1474.

43. Calabrese, E. J.; Baldwin, L. A., The dose determines the stimulation (and poison): development of a chemical hormesis database. International Journal of Toxicology 1997, 16, (6), 545559.

44. de la Paz Celorio-Mancera, M.; Ahn, S. J.; Vogel, H.; Heckel, D. G., Transcriptional responses underlying the hormetic and detrimental effects of the plant secondary metabolite gossypol on the generalist herbivore Helicoverpa armigera. BMC genomics 2011, 12.

45. Steinberg, C. E. W.; Pietsch, K.; Saul, N.; Menzel, S.; Swain, S. C.; Stürzenbaum, S. R.; Menzel, R., Transcript Expression Patterns Illuminate the Mechanistic Background of Hormesis in Caenorhabditis elegans Maupas. Dose-Response 2013, 11, (4).

46. Stephen, J., Biochar for environmental management-science and technology. In 2016.

47. Creamer, R. E.; Rimmer, D. L.; Black, H. I. J., Do elevated soil concentrations of metals affect the diversity and activity of soil invertebrates in the long - term? Soil Use and Management 2008, 24, (1), 37-46.

48. Peredney, C. L.; Williams, P. L., Utility of Caenorhabditis elegans for assessing heavy metal contamination in artificial soil. Archives of environmental contamination and toxicology 2000, 39, (1), 113-118.

49. Barsyte, D.; Lovejoy, D. A.; Lithgow, G. J., Longevity and heavy metal resistance in daf-2 and age-1 long-lived mutants of Caenorhabditis elegans. The FASEB Journal 2001, 15, (3), 627-634. 
50. Moyson, S.; Vissenberg, K.; Fransen, E.; Blust, R.; Husson, S. J., Mixture effects of copper, cadmium and zinc on mortality and behaviour of $C$. elegans. Environmental Toxicology and Chemistry 2017, 37, (1), 145-159.

51. Wu, Q.; Li, Y.; Tang, M.; Wang, D., Evaluation of Environmental safety Concentrations of DMSA Coated Fe2O3-NPs Using Different Assay Systems in Nematode Caenorhabditis elegans. PloS one 2012, 7, (8).

52. Park, J. H.; Choppala, G. K.; Bolan, N. S.; Chung, J. W.; Chuasavathi, T., Biochar reduces the bioavailability and phytotoxicity of heavy metals. Plant and Soil 2011, 348, (1-2), 439.

53. Liu, G.; Niu, Z.; Van Niekerk, D.; Xue, J.; Zheng, L., Polycyclic Aromatic Hydrocarbons (PAHs) from Coal Combustion: Emissions, Analysis, and Toxicology. In Reviews of Environmental Contamination and Toxicology, Whitacre, D. M., Ed. Springer: 2008; Vol. 192, pp 1-28.

54. Pelkonen, O.; Raunio, H., Metabolic activation of toxins: Tissue-specific expression and metabolism in target organs. In Environmental health perspectives, 1997; Vol. 105, pp 767-774.

55. Wassenberg, D. M.; Di Giulio, R. T., Synergistic embryotoxicity of polycyclic aromatic hydrocarbon aryl hydrocarbon receptor agonists with cytochrome P4501A inhibitors in Fundulus heteroclitus. Environmental health perspectives 2004, 112, (17), 1658.

56. Steinberg, C. E. W., Stress Ecology: Environmental Stress as Ecological Driving Force and Key Player in Evolution. Springer Science \& Business Media: 2012.

57. Hale, S. E.; Lehmann, J.; Rutherford, D.; Zimmerman, A. R.; Bachmann, R. T.; Shitumbanuma, V.; O'Toole, A.; Sundqvist, K. L.; Arp, H. P. H.; Cornelissen, G., Quantifying the total and bioavailable polycyclic aromatic hydrocarbons and dioxins in biochars. Environmental science \& technology 2012, 46, (5), 2830-2838.

58. Menzel, R.; Bogaert, T.; Achazi, R., A systematic gene expression screen of Caenorhabditis elegans cytochrome P450 genes reveals CYP35 as strongly xenobiotic inducible. Archives of biochemistry and biophysics 2001, 395, (2), 158-168.

59. Menzel, R.; Rödel, M.; Kulas, J.; Steinberg, C. E. W., CYP35: Xenobiotically induced gene expression in the nematode Caenorhabditis elegans. Archives of biochemistry and biophysics 2005, 438, (1), 93-102.

60. Steinberg, C. E. W.; Timofeyev, M. A.; Menzel, R., Dissolved Humic Substances: Interactions with Organisms. In Encyclopedia of Inland Waters, Likens, G. E., Ed. Academic Press: 2009.

61. Pilawa, B.; Wieckowski, A. B.; Pietrzak, R.; Wachowska, H., Multi-component EPR spectra of coals with different carbon content. Acta Physica Polonica-Series A General Physics 2005, 108, (2), 403-408.

62. Uttara, B.; Singh, A. V.; Zamboni, P.; Mahajan, R. T., Oxidative Stress and Neurodegenerative Diseases: A Review of Upstream and Downstream Antioxidant Therapeutic Options. Current Neuropharmacology 2009, 7, (1), 65-74.

63. Lin, M. T.; Beal, M. F., Mitochondrial dysfunction and oxidative stress in neurodegenerative diseases. Nature 2006, 443, (7113), 787-795.

64. Ristow, M., Unraveling the truth about antioxidants. Nature medicine 2014, 20, (7), 709-711. 


\section{Supporting Information}

\section{Overlooked Risks of Biochar - Persistent Free Radicals trigger Neurotoxicity in C. elegans}

\section{Authors:}

Thora LIEKE ${ }^{\mathrm{a}, \mathrm{b}, \mathrm{c}^{*}}$, Xuchao ZHANG ${ }^{\mathrm{a}}$, Christian E.W. STEINBERG ${ }^{\mathrm{b}}$, Bo PAN ${ }^{\mathrm{a},{ }^{*}}$

${ }^{a}$ Faculty of Environmental Science and Engineering, Kunming University of Science and Technology, 650093 Kunming, China

${ }^{\mathrm{b}}$ Faculty of Life Sciences, Freshwater and Stress Ecology, Humboldt-Universität zu Berlin, Späthstr. 80/81, 12437 Berlin, Germany

'Leibnitz-Institute of Freshwater Ecology and Inland Fisheries, Müggelseedamm 310, 12587 Berlin, Germany

*Corresponding authors (lieke@igb-berlin.de; panbocai@aliyun.com)

\section{Content:}

Table S1-S6

Pages: 2 
Table S 1: Elemental composition of biochar

\begin{tabular}{|l|c|c|c|c|c|}
\hline Element & $\mathbf{N}$ & $\mathbf{C}$ & $\mathbf{H}$ & $\mathbf{S}$ & $\mathbf{0}$ \\
\hline Mean & 1.14 & 55.50 & 1.95 & 0.34 & 7.99 \\
\hline SEM & 0.01 & 0.46 & 0.02 & 0.01 & 0.08 \\
\hline
\end{tabular}

Table S 2: Locomotion behavior

\begin{tabular}{|c|c|c|c|c|c|}
\hline \multicolumn{6}{|c|}{ Body bends $\left[\mathrm{min}^{-1}\right]$} \\
\hline Sample & $0 \mathrm{mg} \mathrm{C} / \mathrm{L}$ & $250 \mathrm{mg} \mathrm{C} / \mathrm{L}$ & $500 \mathrm{mg} \mathrm{C} / \mathrm{L}$ & $1000 \mathrm{mg} \mathrm{C} / \mathrm{L}$ & $2000 \mathrm{mg} \mathrm{C} / \mathrm{L}$ \\
\hline Mean & 47.69 & 51.75 & 48.28 & 44.23 & 41.38 \\
\hline SEM & 0.97 & 1.08 & 1.05 & 1.22 & 1.17 \\
\hline Significance & & 0.007 & 0.683 & 0.027 & $<0.001$ \\
\hline \multicolumn{6}{|c|}{ Relative movement $\left[20 \mathrm{~s}^{-1}\right]$} \\
\hline Sample & $0 \mathrm{mg} \mathrm{C} / \mathrm{L}$ & $250 \mathrm{mg} \mathrm{C} / \mathrm{L}$ & $500 \mathrm{mg} \mathrm{C} / \mathrm{L}$ & $1000 \mathrm{mg} \mathrm{C} / \mathrm{L}$ & $2000 \mathrm{mg} \mathrm{C} / \mathrm{L}$ \\
\hline Mean & 4.49 & 4.87 & 4.57 & 3.96 & 3.58 \\
\hline SEM & 0.13 & 0.09 & 0.26 & 0.18 & 0.12 \\
\hline Significance & & 0.02 & 0.78 & 0.02 & $<0.001$ \\
\hline
\end{tabular}

Table S 3: Defecation interval

\begin{tabular}{|c|c|c|c|c|c|}
\hline \multicolumn{6}{|c|}{ Defecation intervall [s] } \\
\hline Sample & $0 \mathrm{mg} \mathrm{C} / \mathrm{L}$ & $250 \mathrm{mg} \mathrm{C} / \mathrm{L}$ & $500 \mathrm{mg} \mathrm{C} / \mathrm{L}$ & $1000 \mathrm{mg} \mathrm{C} / \mathrm{L}$ & $2000 \mathrm{mg} \mathrm{C} / \mathrm{L}$ \\
\hline Mean & 59.70 & 58.38 & 59.75 & 65.58 & 65.58 \\
\hline SEM & 1.00 & 1.15 & 1.27 & 1.47 & 1.00 \\
\hline Significance & & 0.388 & 0.975 & 0.001 & $<0.001$ \\
\hline
\end{tabular}

Table S 4: Pumping

\begin{tabular}{|c|c|c|c|c|c|}
\hline \multicolumn{6}{|c|}{ Pumping-frequency $\left[\mathrm{min}^{-1}\right]$} \\
\hline Sample & $0 \mathrm{mg} \mathrm{C} / \mathrm{L}$ & $250 \mathrm{mg} \mathrm{C} / \mathrm{L}$ & $500 \mathrm{mg} \mathrm{C} / \mathrm{L}$ & $1000 \mathrm{mg} \mathrm{C} / \mathrm{L}$ & $2000 \mathrm{mg} \mathrm{C} / \mathrm{L}$ \\
\hline Mean & 257.90 & 241.72 & 246.65 & 258.30 & 247.73 \\
\hline SEM & 3.19 & 3.33 & 3.38 & 3.71 & 3.32 \\
\hline Significance & & 0.209 & 0.383 & 0.913 & 0.393 \\
\hline
\end{tabular}

Table S 5: Mechanical sensory

\begin{tabular}{|c|c|c|c|c|c|}
\hline \multicolumn{6}{|c|}{ Affirmative responses to mechanical stimulation [\%] } \\
\hline Sample & $0 \mathrm{mg} \mathrm{C} / \mathrm{L}$ & $250 \mathrm{mg} \mathrm{C} / \mathrm{L}$ & $500 \mathrm{mg} \mathrm{C} / \mathrm{L}$ & $1000 \mathrm{mg} \mathrm{C} / \mathrm{L}$ & $2000 \mathrm{mg} \mathrm{C} / \mathrm{L}$ \\
\hline Mean & 94.00 & 94.67 & 97.50 & 93.00 & 91.00 \\
\hline SEM & 1.49 & 1.15 & 0.99 & 1.67 & 1.68 \\
\hline Significance & & 0.724 & 0.193 & 0.656 & 0.187 \\
\hline
\end{tabular}

Table S 6: Chemical sensory

\begin{tabular}{|l|l|l|l|l|l|}
\hline \multicolumn{5}{|l|}{ Chemical index } \\
\hline Sample & $\mathbf{0} \mathbf{~} \mathbf{g} \mathbf{C} / \mathbf{L}$ & $\mathbf{2 5 0} \mathbf{~} \mathbf{~ C / L}$ & $\mathbf{5 0 0} \mathbf{~ g ~ C / L}$ & $\mathbf{1 0 0 0} \mathbf{~ g ~ C / L}$ & $\mathbf{2 0 0 0} \mathbf{~} g$ C/L \\
\hline Mean & 0.18 & 0.20 & 0.21 & 0.20 & 0.16 \\
\hline SEM & 0.02 & 0.02 & 0.05 & 0.07 & 0.06 \\
\hline Significance & & 0.490 & 0.724 & 0.839 & 0.713 \\
\hline
\end{tabular}

